12 LaRosa JC, He J, Vupputuri S. Effect of statins on risk of coronary disease: a meta-analysis of randomized controlled trials. JAMA 1999:282:2340-6 $13 \mathrm{MRC} / \mathrm{BHF}$ heart protection study of cholesterol lowering with simvastatin in 20,536 high-risk individuals: a randomised placebo-controlled trial. Lancet 2002;360:7-22.

14 Alter DA, Manuel DG, Gunraj N, Anderson G, Naylor CD, Laupacis A. Age, risk-benefit trade-offs, and the projected effects of evidence-based therapies. Am J Med 2004;116:540-5.

15 Jackevicius CA, Mamdani M, Tu JV. Adherence with statin therapy in elderly patients with and without acute coronary syndromes. JAMA 2002;288:462-7.
16 Clemenson ND. Statins and risk of coronary heart disease. JAMA $2000 \cdot 283 \cdot 2935$.

17 D'Agostino RB Sr, Grundy S, Sullivan LM, Wilson P. Validation of the Framingham coronary heart disease prediction scores: results of a multiple ethnic groups investigation. JAMA 2001;286:180-7.

18 Hense HW. Observations, predictions and decisions-assessing cardiovascular risk assessment. Int J Epidemiol 2004;33:235-9.

(Accepted 1 April 2006)

doi 10.1136/bmj.38849.487546.DE

\title{
Commentary: Cardiovascular risk estimation: important but may be inaccurate
}

Vishnu Madhok, Tom Fahey

Division of

Community Health

Sciences, Mackenzi

Building, University

of Dundee, Dundee

DD2 4BF

Vishnu Madhok

medical student

Tom Fahey

professor of primary

care medicine

Correspondence to:

T Fahey

t.p.fahey@

chs.dundee.ac.uk
Manuel and colleagues applied the recommendations from six national guidelines on statin treatment to the same Canadian population and measured each guideline's impact in terms of number of people recommended for treatment, potential number of deaths from coronary heart disease avoided, and the number needed to treat to avoid one death. ${ }^{1}$ They show that markedly different numbers of people are recommended for treatment when different guidelines are followed.

Deciding whether to prescribe statins for a patient for the primary prevention of coronary heart disease would seem to be a relatively straightforward issue in the broader context of decision making in primary care. Over the past 10 years, 14 randomised controlled trials have established the efficacy of statins across a broad range of patient groups. ${ }^{2}$ However, as Manuel and colleagues show, integration of evidence into clinical guidelines is inconsistent, particularly with regard to explicit use of Framingham and other multivariable risk functions when estimating the probability of heart disease developing in individual patients. ${ }^{1}$

Some would argue that the results of Manuel and colleagues' study are not surprising, as the outcome for their study-death from coronary heart disease-was calculated by applying the Framingham or SCORE risk score, an example of internal validity assessment. The guidelines that go furthest in recommending calculation of absolute risk-New Zealand, British, and Australian-would be expected to perform better than those that are less explicit-US, Canadian, and European. As the relative benefits from statins are constant irrespective of initial absolute risk and the risks of treatment are small, the approach of explicit absolute risk assessment is justified: higher risk individuals are likely to gain the most in absolute terms. ${ }^{12}$

Equally, uncritical application of absolute risk assessment for primary prevention of coronary heart disease should be discouraged. A systematic review of 27 external validity studies, of the extent to which predicted risk assessments are an accurate reflection of observed risk of heart disease, shows that the performance of the Framingham risk score varies considerably between different countries and populations. ${ }^{3}$ Predicted to observed ratios ranged from an underprediction of 0.43 in higher risk populations to overprediction of 2.87 in lower risk populations. ${ }^{3}$ Within the United Kingdom, regional differences of risk of heart disease mean that the accuracy of Framingham varies, with overprediction in areas of low incidence of $\mathrm{CHD}^{4}$ and underestimation in socially deprived areas, where the incidence of heart disease is high. ${ }^{5}$ Even if Framingham was consistently accurate, evidence about the benefits of applying absolute risk assessment in the primary prevention of heart disease is scarce; only four randomised controlled trials implementing this approach have been published, with inconclusive results. ${ }^{3}$

In conclusion, the study by Manuel and colleagues contains an important message. Explicit absolute risk assessment is an essential starting point when considering primary preventive treatment for CHD. However, uncritical application of Framingham may mislead patients and health professionals and ongoing studies are needed to ensure $\mathrm{CHD}$ risk assessment is as accurate as possible for the group of patients to which it is applied.

Manuel DG, Kwong K, Tanuseputro P, Lim J, Mustard CA, Anderson GM, et al. Effectiveness and efficiency of different guidelines on statin et al. Effectiveness and efficiency of different guidelines on statin
treatment for preventing deaths from coronary heart disease: modelling study. BMJ 2006:332:1419-22

2 Cholesterol Treatment Trialists' (CCT) Collaborators. Efficacy and safety of cholesterol-lowering treatment: prospective meta-analysis of data from 90,056 participants in 14 randomised trials of statins. Lancel 2005;366:1267-78.

3 Brindle P, Beswick A, Fahey T, Ebrahim S. The accuracy and impact of risk assessment in the primary prevention of cardiovascular disease: a systematic review. Heart 2006 Apr 18; [Epub ahead of print].

4 Brindle P, Emberson J, Lampe F, Walker M, Whincup P, Fahey T, et al. Predictive accuracy of the Framingham coronary risk score in British Predictive accuracy of the Framingham coronary risk

Brindle PMect Brindle PM, McConnachie A, Upton MN, Hart CL, Smith GD, Watt GCM.
The accuracy of the Framingham risk-score in different socioeconomic The accuracy of the Framingham risk-score in different so
groups: a prospective study. BrJ Gen Pract 2005;55:838-45. (Accepted 9 May 2006)

doi 10.1136/bmj.38849.517257.DE

This article was posted on bmi.com on 31 May 2006: http://bmi.com/cgi/ doi/10.1136/bmj.38849.517257.DE

\section{Endpiece}

\section{Distress}

If you are distressed by anything external, the pain is not due to the thing itself, but to your estimate of it; and this you have the power to revoke at any moment.

Marcus Aurelius Antoninus (AD 121-180)

Submitted by Luke Cascarini, senior house officer, Queen Victoria Hospital, East Grinstead 